Canadian

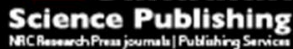

Canadian Geotechnical Journal Revue canadienne de géotechnique

\title{
Evaluation of Jet Grout Column Diameters by Acoustic Monitoring
}

\begin{tabular}{|r|l|}
\hline Journal: & Canadian Geotechnical Journal \\
\hline Manuscript ID & cgj-2017-0025.R2 \\
\hline Danuscript Type: & Note \\
\hline Complete List of Authors: & $\begin{array}{l}\text { Cheng, Shih-Hao; National Taiwan University of Science and Technology, } \\
\text { Taiwan Building Technology Center (TBTC) } \\
\text { Liao, Hung-Jiun; National Taiwan University of Science and Technolog, Civil } \\
\text { and construction engineering } \\
\text { Yamazaki, Junichi; SanShin Corporation, Technical Division } \\
\text { Wong, Ricky K. N.; SanShin Corporation, Taipei Branch }\end{array}$ \\
\hline Keyword: & jet grouting, column diameter, acoustic monitoring, normal distribution \\
\hline \multicolumn{2}{|c}{} \\
\hline
\end{tabular}

SCHOLARONE ${ }^{1 m}$

Manuscripts 


\title{
Evaluation of Jet Grout Column Diameters by Acoustic Monitoring
}

\author{
Shih-Hao Cheng ${ }^{1}$, Hung-Jiun Liao ${ }^{2}$, Junichi Yamazaki ${ }^{3}$, and Ricky K. N. Wong ${ }^{4}$
}

\begin{abstract}
To evaluate the diameter of jet grout columns actually formed under the ground, several methods had been developed over the past years. Nevertheless, uncertainty still exists in different methods mostly due to the variations of ground and grouting conditions. This study proposes an acoustic monitoring system capable to directly record the jet grouting sounds picked up at different distances from the jet nozzle. To correlate the actual diameter of the jet grout column with the monitored sound prints, a field test was conducted in an interlayered sandy and gravelly soil and the jet grout column was excavated for dimension measurement. The recorded sound show that the distribution of the threshold peak amplitudes at different distances can be represented by the curve of normal distribution function. In addition, the standard deviation and the mean of the normally distributed threshold peak amplitudes can be used as indicators to determine the effective diameter of the jet grout column for a specific jet grouting project. Although this acoustic monitoring method would be costly and time consuming to examine all jet grout columns, it is suitable for frequent use in trial tests for finding reasonable grouting parameters to form jet gout columns with design diameter.
\end{abstract}

Keywords: jet grouting; column diameter; acoustic monitoring; normal distribution

\footnotetext{
${ }^{1}$ Assistant Professor, Taiwan Building Technology Center, National Taiwan University of Science and Technology, Taipei, Taiwan (Corresponding Author)

${ }^{2}$ Professor, Department of Civil and Construction Engineering, National Taiwan University of Science and Technology, Taipei, Taiwan

${ }^{3}$ Manager, Technical Division, SanShin Corporation, Tokyo, Japan

${ }^{4}$ Taipei Branch Manager, Taipei Branch, SanShin Corporation, Taipei, Taiwan
} 


\section{INTRODUCTION}

Jet grouting has been widely used in urban geotechnical engineering works to ensure the stability and waterproofing required for geotechnical construction. Selecting the most suitable system for a particular job site depends on the subsoil and surrounding conditions as well as the characteristics of the jet grout work required. Over the past few decades, considerable progress has been made in jet grouting technology, especially in increasing the jet grout column diameter and improving the jet grouting equipment (Brill et al. 2003; Yoshida 2010; Burke 2012). Of these, the diameter of jet grout columns can be controlled by properly adjusting the grouting parameters, such as the pressure and flow rate of the jetting fluid, jetting time, and jet nozzle size. It is not uncommon to construct a jet grout column with a diameter exceeding $5 \mathrm{~m}$. Jet grout columns with larger diameters have certain advantages, especially for the ground improvement work such as the preparation grouting work for the launching or receiving of tunnel-boring machines (TBM) in soft ground under groundwater level. By increasing the jet grout column diameter, less grout holes are needed to drill. Therefore, it has to be sure that the jet grout columns formed in the ground can achieve the diameter required by the engineer. This study proposes a direct method to evaluate the diameter of jet grout columns using an acoustic monitoring system, which can digitally record the sound generated from the impact of grout jet on the embedded monitoring pipes that are placed at different distances from the jet nozzle.

\section{LITERATURE REVIEWS}

During jet grouting, the subsoil is eroded by a high-speed fluid jet and mixed with the injected grout to form a jet grout column. Estimating the size and shape of jet grout columns formed in the ground is a challenging task. So far, many methods had been proposed to estimate the 
diameter of jet grout columns. Some methods are empirical (Shibazaki 2003; Mihalis et al. 2004; Flora et al. 2013); some are theoretical (Modoni et al. 2006; Wang et al. 2012) or semitheoretical (Shen et al. 2013; 2014). But all the mentioned methods used indirect estimation on the diameters of jet grout columns. In addition to the above indirect estimation of the empirical or theoretical methods, some direct estimation methods had been developed also. They are based on in situ temperature measurements, ultrasonic measurements, and electrical resistivity measurements etc. (Brandstätter et al. 2005; Frappin 2011; Bearce et al. 2014). These methods entail taking the physical characteristic change in the cement-soil admixture to evaluate the jet grout column diameter. However, these methods can be influenced by environmental factors and cannot produce results in real time. Therefore, to estimate the column diameter formed by the jet grouting method, an acoustic monitoring system using digital recording method is proposed here. This system is different from the earlier jet-sounding technique which used only microphone and headset to receive and broadcast the sound generated during jet grouting (Fang et al. 2006). Little quantitative information could be gathered from this earlier method.

\section{ACOUSTIC MONITORING SYSTEM FOR JET GROUTING}

To obtain digitally monitored sound for estimating the effective cutting distance of the grout jet, an acoustic monitoring system was used in this study. It consisted of four main components: a waterproof geophone, monitoring pipes, a geophone lift-up device and control unit, and a digital sound recording unit (Fig. 1a). During the monitoring process of this study, the geophone was lowered into the monitoring pipe to collect the sound data generated by jet grouting. To synchronize the lift-up rate of the geophone and jet nozzle, the geophone was mounted on an automatic lift-up device. It was to ensure that the sound recorded was generated by the grout jet 
hitting the monitoring pipe at the same depth and same angle each time; thus, the variations in the monitored sound prints due to the changing jet impact angle can be minimized.

This acoustic monitoring system is capable of recording the amplitude of sound prints ranging from 26 to $130 \mathrm{~dB}$ with a sampling rate of $0.1 \mathrm{sec}$ per reading. The recorded sound data were displayed by magnifying the data 10 times in the recording unit. For example, if the output magnitude of the sound is shown as 655 , it means the actual magnitude of the sound was 65.5 $\mathrm{dB}$. The monitoring pipe is made of seamless steel, which has an outer diameter of $76.3 \mathrm{~mm}$ and a thickness of $4.2 \mathrm{~mm}$. The monitoring pipe was inserted into the drill hole and the annular gap between the drill hole and pipe can be backfilled with cement-bentonite grout to increase its stability and ensure the full contact with grouted soil. Monitoring pipes were placed at multiple distances from the jet nozzle (Fig. 1b), and the internal sections of the monitoring pipes were filled with water during monitoring period to improve the sound detection quality of the geophones. To ensure that recorded cutting sounds is informative, this study suggests to setting up at least three monitoring pipes: one within the design diameter, another at the design diameter, and the third outside the design diameter.

Although the proposed acoustic monitoring system can provide a straightforward way to measure the grout column diameter formed by jet grouting method, it needs additional effort, time and cost to carry out such works. So it is not suggested to apply to all jet grouting projects. But it can still be useful if applied to a jet grouting site with limited dimension and high risk potential, such as the jet grouting work for the launching or receiving of TBM in sandy soil formation under groundwater level. 


\section{FULL SCALE FIELD TEST}

A jet grouting field test was carried out to demonstrate the suitability of the acoustic monitoring system to record the impact sound of a grout jet on monitoring pipes (Shinsaka and Yamazaki 2013). The design diameter of the jet grout column $\left(D_{d}\right)$ was $3.5 \mathrm{~m}$ and the jet grout column was located from 4.5 to $6.0 \mathrm{~m}$. The subsoil condition of the test site, jet grouting method, formation of the jet grout column, and the monitored sound data are described as follows.

\section{Subsoil Conditions}

The subsoil conditions of the test site consisted of an interlayered sand and gravel formation (Fig. 2). The groundwater level was nearly $4.0 \mathrm{~m}$ below the ground surface. The jet grouting zone covered both the sand layer (upper) and the gravelly sand layer (lower). The SPT-N values in the sand layer were below 20 (from 4.5 to $5.0 \mathrm{~m}$ ), and they varied from 20 to 50 in the gravelly sand layer (below $5.0 \mathrm{~m}$ ). The natural water content $\left(\omega_{\mathrm{n}}\right)$ ranged from 24 to $32 \%$, and the unit weight $\left(\gamma_{t}\right)$ of the interlayered sand and gravel formation varied from 17.8 to $19.4 \mathrm{kN} / \mathrm{m}^{3}$. The particle size distribution in the jet grouted zone is shown in Fig. 3, indicating that the average particle size of the soil $\left(\mathrm{D}_{50}\right)$ is approximately $0.3 \mathrm{~mm}$ and the fines $(<0.075 \mathrm{~mm})$ content is less than $5 \%$. This was particularly clean sand for grouting.

\section{Jet Grouting Method}

This study used a double-fluid jet grouting system, commercially named the V-Jet method. The jet grouting parameters adopted for the V-Jet method are close to those proposed by Burke (2004) and Lunardi (1997). The grout jet was shrouded with compressed air $\left(\mathrm{p}_{\mathrm{a}}=0.9 \mathrm{MPa}\right)$ to 
enhance its cutting ability and cutting distance while also enhancing the mixing of cement grout with the in-situ soil. Two nozzles were mounted on the opposite side of the monitor with a 25 $\mathrm{mm}$ difference in elevation. The grouting parameters used for this field test are listed in Table 1. The jetting pressure $\left(\mathrm{p}_{\mathrm{g}}\right)$ and flow rate $\left(\mathrm{q}_{\mathrm{g}}\right)$ of the jet grouting test were $37 \mathrm{MPa}$ and $6.7 \times 10^{-3}$ $\mathrm{m}^{3} / \mathrm{sec}$ (i.e., $3.3 \times 10^{-3} \mathrm{~m}^{3} / \mathrm{sec}$ per nozzle) respectively; the nozzle diameters $\left(\mathrm{d}_{0}\right)$ was $4.4 \mathrm{~mm}$. With this flow rate and nozzle size combination, the exit jet velocity $\left(\mathrm{v}_{0}\right)$ from the nozzle was approximately $215 \mathrm{~m} / \mathrm{sec}$. The revolution rate $\left(\mathrm{R}_{\mathrm{s}}\right)$ was $0.52 \mathrm{rad} / \mathrm{sec}$, and the lift-up rate $\left(\mathrm{v}_{\mathrm{s}}\right)$ of the nozzle was $1.67 \times 10^{-3} \mathrm{~m} / \mathrm{sec}$. The lift-up step $\left(\Delta \mathrm{S}_{\mathrm{t}}\right)$ was set to $5 \mathrm{~cm} / \mathrm{step}$.

\section{Jet Grout Column and Monitored Sound Data}

The jet grout column at the test site was $4.5 \mathrm{~m}$ below the ground surface. Therefore, it could be dug out for visual inspection and dimension measurement. As shown in Fig. 4a, the actual diameter was nearly $4.5 \mathrm{~m}$ compared with the design column diameter $\left(\mathrm{D}_{\mathrm{d}}\right)$ of $3.5 \mathrm{~m}$. The visual inspection results of all the monitoring pipe locations are shown in Fig. 4b. Four monitoring pipe were set up in the field test to collect jet grouting sounds, two within the design diameter and the other two outside this diameter. The average column diameters $\left(\mathrm{D}_{0}\right)$ measured in the field test were $4.6 \mathrm{~m}$ in Section 1-1' and $4.5 \mathrm{~m}$ in Section 2-2' (Fig. 5). The unconfined compressive strength $\left(\mathrm{q}_{\mathrm{ug}}\right)$ of the 10-day cured samples varied from 3 to $8 \mathrm{MPa}$ and the coefficient of hydraulic conductivity $\left(\mathrm{k}_{\mathrm{g}}\right)$ was approximately $2.0 \times 10^{-8} \mathrm{~cm} / \mathrm{sec}$. In comparison, the unconfined compressive strength and the coefficient of hydraulic conductivity of the in-situ soil were respectively 0.55 to $0.65 \mathrm{MPa}\left(\mathrm{q}_{\mathrm{u}}\right)$ and $5 \times 10^{-2}$ to $3 \times 10^{-3} \mathrm{~cm} / \mathrm{sec}(\mathrm{k})$. The grouting parameters adopted in the field test were capable of forming a grout column with a large diameter (nearly $4.5 \mathrm{~m}$ ) under the ground conditions of the test site. 
As Fig. $1 \mathrm{~b}$ and Fig. $4 \mathrm{~b}$ show, the monitoring pipes were placed at radial distances of $\mathrm{r}=1.5 \mathrm{~m}, \mathrm{r}_{\mathrm{d}}$ $=1.75 \mathrm{~m}$ (the design diameter), $\mathrm{r}=2.0 \mathrm{~m}$ and $\mathrm{r}=2.25 \mathrm{~m}$ from the nozzle. During jet grouting, peak sounds were generated at a constant time interval depending on the revolution rate of the nozzle (Fig. 6). However, the peak sound attenuated with increasing distance from the nozzle. When the nozzle rotated away from the monitoring pipe, the monitored sound decreased gradually from the peak to the background sound of the acoustic monitoring work.

\section{DATA PROCESSING OF MONITORED SOUND PRINTS}

The sound prints were taken from the monitoring pipe at the distance of $\mathrm{r}=1.5 \mathrm{~m}$ are used here to illustrate that sound prints recorded by the acoustic monitoring device generally included the peak sound, the background sound and random noise (Fig. 7a). To better interpret the sound prints recorded at different distances, the random noise had to be reduced. Since the drill rod and jet nozzles revolved at a constant rate, sounds with a regular period were recorded. Under this circumstance, detecting any significant difference in the frequency spectrum is difficult. By contrast, an amplitude-modulated wave could be observed in the time-domain processing of the sound prints (Smith 1997; Sujatha 2010). Therefore, the time waveform could be used to reduce the random noise from the monitored sound prints.

The monitored sound prints from the field test would be affected by soil properties and jetting fluid properties, which create various degrees of random noise. To reduce this noise and extract the required information (peak amplitudes) from the noise reduced sound prints of jet grouting, time-synchronous-averaging (TSA) and peak-over-threshold (POT) methods were used to 
facilitate the analysis process. Meanwhile, to establish the correlation between discrete peak amplitudes and jet cutting distance, the normal distribution function was used to illustrate the attenuation of peak sound amplitudes with distance.

\section{Noise Reduction by Time-Synchronous-Averaging}

TSA is a time-domain signal-processing technique that extracts periodic waveforms from noisy data (Braun 1975; McFadden and Toozhy 2000). TSA processing is operated by averaging a number of points from the input point chosen symmetrically around the output point. Usually, if a monitored sound print $x[]$ is recorded, then a monitored sound print after random noise reduction (TSA processing) $y[$ can be obtained as follows:

$y[i]=\frac{1}{M} \sum_{j=-(M-1) / 2}^{(M-1) / 2} x[i+j]$

where $M$ is the number of points in the moving average. $M$ is an odd number in TSA processing, and is chosen depending on the random noise reduction requirement. The indices $i$ and $j$ represent the data point and the moving average point, respectively.

To demonstrate the effects of TSA processing on the monitored sound prints, Fig. 7 presents an example using the sound data from the monitoring pipe at the distance of $\mathrm{r}=1.5 \mathrm{~m}$ with different values of $M$ in eq. (1). The effect of TSA processing on reducing the random noise changes from "not obvious" to "very obvious" when the numbers of moving average point increase from $M=3$ to $M=19$ and 27 (Fig. 7b to Fig. 7e). However, the sharpness of the sound waveform is reduced 
in the process and loses the characteristics of monitored sound prints as well (Fig. 7d and Fig. 7e). The number of moving average points $M=11$ was chosen as the optimal number for this study (Fig. 7c). It roughly reduces the random noise by $7.5 \mathrm{~dB}$ (a reading of 75 divided by 10), and almost no random noise is found in the background sound after TSA processing. The random noise content and the attenuation of the background sound amplitude were not considerably changed even under the conditions of increased distance and reduced sound amplitude. This means that the amplitude of the background sound is influenced by soil types rather than grouting parameters such as jetting pressure and flow rate.

\section{Extracted Peaks/Troughs of Monitored Sound Prints}

The correlation between the sound amplitude and actual jet grout column diameter should be established from the monitored sound prints. To extract useful information from the noise reduced sound prints, POT analysis was adopted using the sound intensity and peak amplitude as the indices. As shown in Fig. 7c, the mean of the noise reduced sound print can be considered the threshold level. The threshold peak is the highest peak amplitude that exceeds the threshold level, and the threshold trough is the lowest trough amplitude below the threshold level. Using the threshold peak and trough, one could capture the peak and trough amplitudes at different depths from the noise reduced sound prints of jet grouting. Figure 8 illustrates the threshold peaks and troughs along the jet grouting depth. The sound intensity and peak amplitude decreased quickly with increasing distance from the jet nozzle, whereas, the trough amplitude remained between 40 and $45 \mathrm{~dB}$. The amount of variation may change with soil types rather than grouting parameters. Therefore, the peak amplitude of the monitored sound can be an important indicator for 
evaluating the cutting capacity and reflects the different parameters of the grout jet and the actual column diameter.

\section{THRESHOLD PEAK DISTRIBUTION AT DIFFERENT DISTANCES}

The energy and velocity of the grout jet decay with the distance from the nozzle when the jet travels through a viscous fluid such as the soil-cement fluid. Typically, as shown in Fig. 9, the intensity of the jet forces is more concentrated and the peak value is higher when close to the jet nozzle. However, the intensity of the concentrated jet attenuates and diffuses with distance. When close to the nozzle, the threshold peak amplitudes recorded by the acoustic monitoring system varied only over a narrow range and with high peak amplitudes. This indicates that the concentrated jet has good cutting capacity. With increasing distance from the nozzle, however, the jet capacity tended to decrease and drop to a level that could no longer cut the soil.

Based on the illustration of Fig. 9, the normal distribution function is used here to represent the distribution of the recorded threshold peak amplitudes from the field. Figure 10 shows the distribution of the threshold peak amplitudes picked up by four monitoring pipes at different distances. The distribution of the threshold peak amplitudes at different distances is typically a left-skewed distribution (i.e., the mean is to the left of the peak). All four monitoring pipes showed that more than half of the monitored threshold peak amplitudes were higher than the mean value $(\mu)$ and all the threshold peak amplitudes were distributed within \pm 3 standard deviations $(\mu \pm 3 \sigma)$. As shown in Fig. 5a, the monitoring pipe at $r=2.25 \mathrm{~m}$ was located at the zigzag border of the jet grout column. The grout jet could generate a sharp peak amplitude when it had a direct hit on the monitoring pipe, but this dropped to a blurred peak amplitude when the 
monitoring pipe was partially buried in the soil and partially exposed to the grout jet. Therefore, when a sudden change on the standard deviations of threshold peak amplitude is detected (for example, 2.9-3.2 dB $\rightarrow 4.6 \mathrm{~dB}$ at $\mathrm{r}=2.25 \mathrm{~m}$ in the interlayered sand and gravelly soil), it indicates that jet force has become less concentrated. The corresponding mean value of the threshold peak amplitudes $(\mu)$ is to be treated as the number which defines the effective diameter of the jet grout column. So, the mean $(=50.7 \mathrm{~dB})$ of threshold peak amplitudes at the distance of $\mathrm{r}=2.25 \mathrm{~m}$ can be used to define the effective jet cutting distance of jet grout when both the sand layer and gravelly sand layer were considered together (Fig. 10a). However, when the sand layer and gravelly sand layer were considered separately, the mean of the threshold peak amplitudes used to define the effective jet cutting distance changes to $53.0 \mathrm{~dB}$ in the sand layer and $49.7 \mathrm{~dB}$ in the gravelly sand layer (Fig. 10b and Fig. 10c). Therefore, the standard deviation $(\sigma)$ and the mean $(\mu)$ of the threshold peak amplitudes can be used as indicators to determine the cutting limit of the grout jet. As obtained in this study, they are $\sigma=4.6 \mathrm{~dB}$ and $\mu=50.7 \mathrm{~dB}$ for the sand/gravelly sand interlayer; $5.0 \mathrm{~dB}$ and $53.0 \mathrm{~dB}$ for the sand layer; and $4.2 \mathrm{~dB}$ and $49.7 \mathrm{~dB}$ for the gravelly sand layer (Table 2).

Figure 11a shows the attenuation rates of the mean threshold peak amplitudes in three different soil formations, namely the sand and gravelly sand interlayer $(5<\mathrm{SPT}-\mathrm{N}<50)$, gravelly sand layer $(20<$ SPT-N $<50)$, and sand layer $(5<$ SPT-N $<20)$, indicating their attenuation rates with distance are equal be $18.0,19.64$, and $14.68 \mathrm{~dB} / \mathrm{m}$ respectively. These numbers show that greater soil strength yields a larger attenuation rate on threshold peak amplitudes inside the effective cutting distance. Furthermore, the standard deviation of threshold peak amplitudes was maintained within the $2.9-3.2 \mathrm{~dB}$ range before the grout jet reached its cutting limit. In 
comparison, there was a clear jump to $4.2-5.0 \mathrm{~dB}$ when the cutting limit of the grout jet was reached (Fig. 11b). The increase in standard deviation is an indication of the mixed sound prints from the impacts of the grout jet on the monitoring pipe located at the cutting limit of the grout jet.

\section{CONCLUSIONS}

This study proposes an alternative method for estimating the actual diameter of a jet grout column through an on-site acoustic monitoring system. Based on a full scale field test and the interpretation of monitored sound prints, it can be concluded that this method is suitable for frequent use in trial tests for finding reasonable grouting parameters to form a jet gout column with design diameter. Although it would be costly and needs extra time to examine all jet grout columns, the proposed method can still be useful if applied to jet grouting site with a limited dimension and high risk potential, say the jet grouting work for the launching and receiving of TBM in a sandy soil formation under groundwater level. The following conclusions can be drawn from the findings of this study.

1. Through the measurement of the impact sound generated by grout jet during the jet grouting process, the monitored sound prints can be used to estimate the effective cutting distance of the grout jet. The proposed acoustic monitoring method has shown its capacity to realistically reflect the influence of soil types and grouting parameters on the effective diameter of jet grout column. However, the random noise in the monitored sound data must be reduced first.

2. When jet cutting in different soils, the grout jet has its own cutting characteristics and can be correlated with the threshold peak amplitudes of the sound prints. The standard deviation and the mean of the threshold peak amplitudes monitored from jet grouting are the indicators to 
determine the cutting limit of grout jet (i.e., the effective diameter of the jet grout column).

3. When a sudden change on the standard deviations of threshold peak amplitude is detected, it indicates that jet force has become less concentrated. The corresponding mean value of the threshold peak amplitudes $(\mu)$ can be treated as the number which defines the effective diameter of the jet grout column. The field test results showed that the means of the threshold peak amplitudes dropped to $50.7 \mathrm{~dB}$ for sand/gravelly sand interlayer, $53.0 \mathrm{~dB}$ for sand layer, and $49.7 \mathrm{~dB}$ for gravelly sand layer when the grout jet reached its cutting limit.

4. Based on the data shown in Table 2 and Fig.11, grouters can estimate the effective diameter of a jet grout column formed in the particular grouting site. However, more jet grouting sound data from different soils and sites are required to establish a sound database for jet grouting practice.

\section{ACKNOWLEDGMENTS}

The authors wish to thank the Ministry of Science and Technology (MOST) of Taiwan and SanShin Corporation for partially providing the financial support for this research (Contract No. NSC 102-2622-E-011-003-CC2, and MOST 104-2622-E-011-027-CC2).

\section{REFERENCES}

Bearce, R., Mooney, M., Niederleithinger, E., and Revil, A. 2014. Characterization of simulated soilcrete column curing using acoustic tomography. In Proceedings of ground Improvement and Geosynthetics, Atlanta, Georgia, 23-26 February 2014. American Society of Civil Engineers, New York, pp. 465-474. doi:10.1061/9780784413272.044.

Braun, S. 1975. The extraction of periodic waveforms by time domain averaging. Acta Acustica United with Acustica, 32 (2), 69-77.

Brandstätter, C., Lackner, R., and Mang, H. 2005. In situ temperature measurements provide new 
insight into the performance of jet grouting. Proceedings of the Institution of Civil Engineers - Ground Improvement, 9(4), 163-167. doi: 10.1680/grim.2005.9.4.163.

Brill, G.T., Burke, G.K., and Ringen, A.R. 2003. A ten-year perspective of jet grouting: Advancements in applications and technology. In Proceedings of 3rd International Conference on Grouting and Ground Treatment, New Orleans, Louisiana, 10-12 February 2003. American Society of Civil Engineers, New York, vol. 1, pp. 218-235.

Burke, G.K. 2004. Jet grouting systems: Advantages and disadvantages. In Proceedings of Drilled shafts, Micropiling, Deep mixing, Remedial method, and Specialty foundation systems, Orlando, Florida, 29-31 January 2004. American Society of Civil Engineers, New York, pp. 218-234.

Burke, G. K. 2012. The state of the practice of jet grouting. In Proceedings of 4th International Conference on Grouting and Deep Mixing, New Orleans, Louisiana, 16-18 February 2012. American Society of Civil Engineers, New York, vol. 2, pp. 74-88.

Fang, Y. S., Kao, C. C., Chou, J., Chain, K. F., and Wang, D. R. 2006. Jet grouting with the superjet-midi method. Proceedings of Institution of Civil Engineers-Ground Improvement, 10 (2), 69-76. doi: 10.1680/grim.2006.10.2.69.

Flora, A., Modoni, G., Lirer, S., and Croce, P. 2013. The diameter of single, double and triple fluid jet grouting columns: prediction method and field trial results. Géotechnique, 63(11), 934-945. doi:10.1680/geot.12.P.062.

Frappin, P. 2011. CYLJET - An innovative method for jet grouting column diameter measurement. In Proceedings of 1st International Conference on Engineering Geophysics, Al Ain, United Arab Emirates, 11-14 December 2011. European Association of Geoscientists \& Engineers, Netherlands, pp. 67-74.

Lunardi, P. 1997. Ground improvement by mean of jet grouting. Proceedings of Institution of Civil Engineers-Ground Improvement, 1 (2), 65-85. doi: 10.1680/gi.1997.010201.

Mihalis, I. K., Tsiambaos, G., and Anagnostopoulos, A. 2004. Jet grouting applications in soft rocks: The Athens Metro case. Proceedings of Institution of Civil Engineers-Geotechnical Engineering, 157 (4), 219-228. doi: 10.1680/geng.2004.157.4.219.

Modoni, G., Croce, P., and Mongiovi, L. 2006. Theoretical modelling of jet grouting. Geotechnique, 56 (5), 335-347. doi: 10.1680/geot.2006.56.5.335.

Shen, S. L., Wang, Z. F., Yang, J., and Ho, C. E. 2013. Generalized approach for prediction of 
jet grout column diameter. Journal of Geotechnical and Geoenvironmental Engineering, 139 (12), 2060-2069. doi: 10.1061/(ASCE)GT.1943-5606.0000932.

Shen, S. L., Wang, Z. F., and Ho, C. E. 2014. Current state of the art in jet grouting for stabilizing soft soil. In Proceedings of ground Improvement and Geosynthetics, Shanghai, China, 26-28 May 2014. American Society of Civil Engineers, New York, pp. 107-116. doi: 10.1061/9780784413401.011.

Shibazaki, M. 2003. State of practice of jet grouting. In Proceedings of 3rd International Conference on Grouting and Ground Treatment, New Orleans, Louisiana, 10-12 February 2003. American Society of Civil Engineers, New York, vol. 1, pp. 198-217.

Shinsaka, T., and Yamazaki, J. 2013. Development of high-speed type jet grouting method. In Proceedings of Geotechnics for Sustainable Development, Hanoi, Vietnam, 28-29 November 2013. Vietnamese Society for Soil Mechanics \& Geotechnical Engineering, Hanoi, pp. 425432.

Smith, S. W. 1997. The Scientist and Engineer's Guide to Digital Signal Processing. California Technical Publishing, San Diego, USA, 277-279.

Sujatha, C. 2010. Vibration and Acoustics: Measurement and Signal Analysis. McGraw-Hill Education, New York, USA, 252-256.

Mcfadden, P. D., and Toozhy, M. M. 2000. Application of synchronous averaging to vibration monitoring of rolling element bearings. Mechanical Systems and Signal Processing, 14 (6), 891-906. doi: 10.1006/mssp.2000.1290.

Wang, Z. F., Shen, S. L., and Yang, J. 2012. Estimation of the diameter of jet-grouted column based on turbulent kinematic flow theory. In Proceedings of 4th International Conference on Grouting and Deep Mixing, New Orleans, Louisiana, 16-18 February 2012. American Society of Civil Engineers, New York, vol. 2, pp. 2044-2051.

Yoshida, H. 2010. The progress of jet grouting in the last 10 years in Japanese market. In Proceedings of 35th Annual Conference on Deep Foundations, Hollywood, California, 12-15 October 2010. Deep Foundations Institute, California, pp. 503-514. 


\section{List of Table Captions}

Table 1. Jet grouting parameters used in the test (design diameter $=3.5 \mathrm{~m}$ )

Table 2. Critical means and standard deviations of threshold peak amplitudes at the cutting limit of the grout jet

\section{List of Figure Captions}

Fig. 1. Synchronized acoustic monitoring system for jet grouting: (a) components of the acoustic monitoring system; (b) plan view of monitoring pipe placement

Fig. 2. Subsoil conditions and jet grout zone of test site

Fig. 3. Typical particle size distribution in jet grout zone of test site

Fig. 4. Column dug out for actual measurements and visual inspection of jet cutting distance: (a) actual diameter measured; (b) monitoring pipe locations

Fig. 5. Actual jet grout column profile and measured diameter: (a) actual jet grout column; (b) measured diameter profile (1-1' section); (c) measured diameter profile (2-2' section)

Fig. 6. Sound prints at multiple distances from the jet nozzle during jet grouting

Fig. 7. Partial sound prints and time smoothing action of TSA processing: (a) monitored sound waveform; (b) 3-point moving average; (c) 11-point moving average and POT processing; (d) 19-point moving average; (e) 27-point moving average

Fig. 8. Sound intensity and threshold peak/trough amplitudes at multiple distances from the jet nozzle

Fig. 9. Schematic of jet traveling through a viscous fluid and the attenuation characteristics 
Fig. 10. Normal distribution results of threshold peak amplitudes recorded at multiple distances from the jet nozzle: (a) sand/gravelly sand interlayer $(5<\mathrm{SPT}-\mathrm{N}<50)$; (b) sand layer $(5<$ SPT-N $<20)$; (c) gravelly sand layer $(20<$ SPT-N $<50)$

Fig. 11. Relationship between threshold peak amplitudes and distance from the jet nozzle (a) mean and attenuation rate; (b) standard deviation 


\section{Table Captions}

Table 1. Jet grouting parameters used in the test (design diameter $=3.5 \mathrm{~m})$

\begin{tabular}{|l|c|c|}
\hline \multicolumn{1}{|c|}{ Method } & V-jet method & Unit \\
\hline Parameters & 1.27 & - \\
\hline Water cement ratio, $W / C$ & 0.9 & $\mathrm{MPa}$ \\
\hline Jetting pressure of air, $\mathrm{p}_{\mathrm{a}}$ & 37 & $\mathrm{MPa}$ \\
\hline Jetting pressure of grout, $\mathrm{p}_{\mathrm{g}}$ & $3.3 \mathrm{X} 10^{-3}$ per nozzle & $\mathrm{mm}$ \\
\hline Flow rate of grout, $\mathrm{q}_{\mathrm{g}} / \mathrm{sec}$ & 4.4 & - \\
\hline Nozzle diameter, $\mathrm{d}_{0}$ & 2 & $\mathrm{mad} / \mathrm{sec}$ \\
\hline Number of nozzles on the monitor & 0.52 & $\mathrm{~m} / \mathrm{sec}$ \\
\hline Revolution rate of rod, $\mathrm{R}_{\mathrm{s}}$ & $1.67 \mathrm{X} 10^{-3}$ & $\mathrm{~cm} / \mathrm{step}$ \\
\hline Lift up or withdrawal rate of rod, $\mathrm{v}_{\mathrm{s}}$ & 5 & - \\
\hline Lift up step, $\Delta \mathrm{S}_{\mathrm{t}}$ & 2.5 & - \\
\hline Rod rotation per step & & - \\
\hline
\end{tabular}

Table 2. Critical means and standard deviations of threshold peak amplitudes at the cutting limit of the grout jet

\begin{tabular}{|c|c|c|c|}
\hline $\begin{array}{ll}\text { Peak amplitudes } & \text { Soil layer } \\
\end{array}$ & Sand/gravelly sand interlayer & Sand layer & Gravelly sand layer \\
\hline Mean & $50.7 \mathrm{~dB}$ & $53.0 \mathrm{~dB}$ & $49.7 \mathrm{~dB}$ \\
\hline Standard deviation & $4.6 \mathrm{~dB}$ & $5.0 \mathrm{~dB}$ & $4.2 \mathrm{~dB}$ \\
\hline Attenuation rate & $18 \mathrm{~dB} / \mathrm{m}$ & $14.68 \mathrm{~dB} / \mathrm{m}$ & $19.64 \mathrm{~dB} / \mathrm{m}$ \\
\hline
\end{tabular}




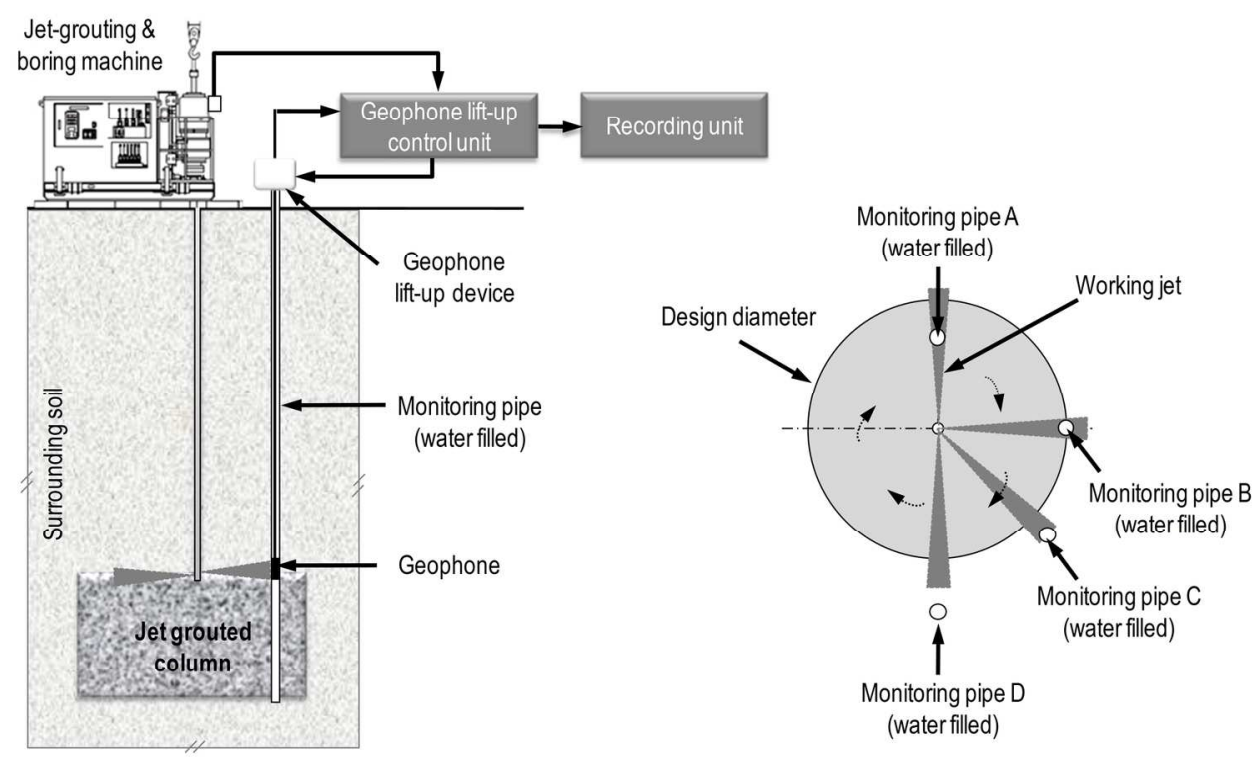

(a)

(b)

Fig. 1. Synchronized acoustic monitoring system for jet grouting: (a) components of the acoustic monitoring system; (b) plan view of monitoring pipe placement

$166 \times 106 \mathrm{~mm}(300 \times 300 \mathrm{DPI})$ 


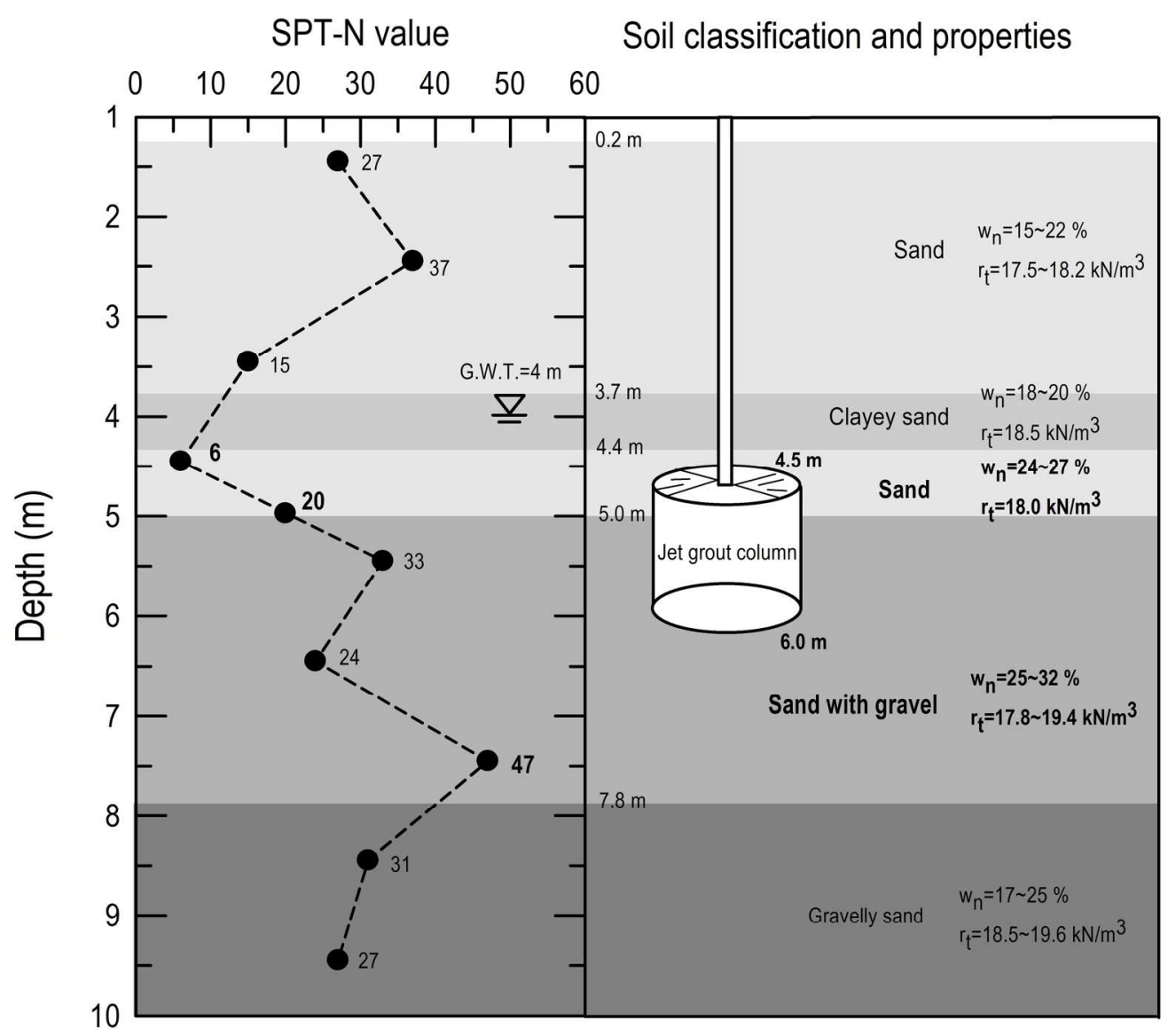

Fig. 2. Subsoil conditions and jet grout zone of test site $173 \times 153 \mathrm{~mm}(300 \times 300 \mathrm{DPI})$ 


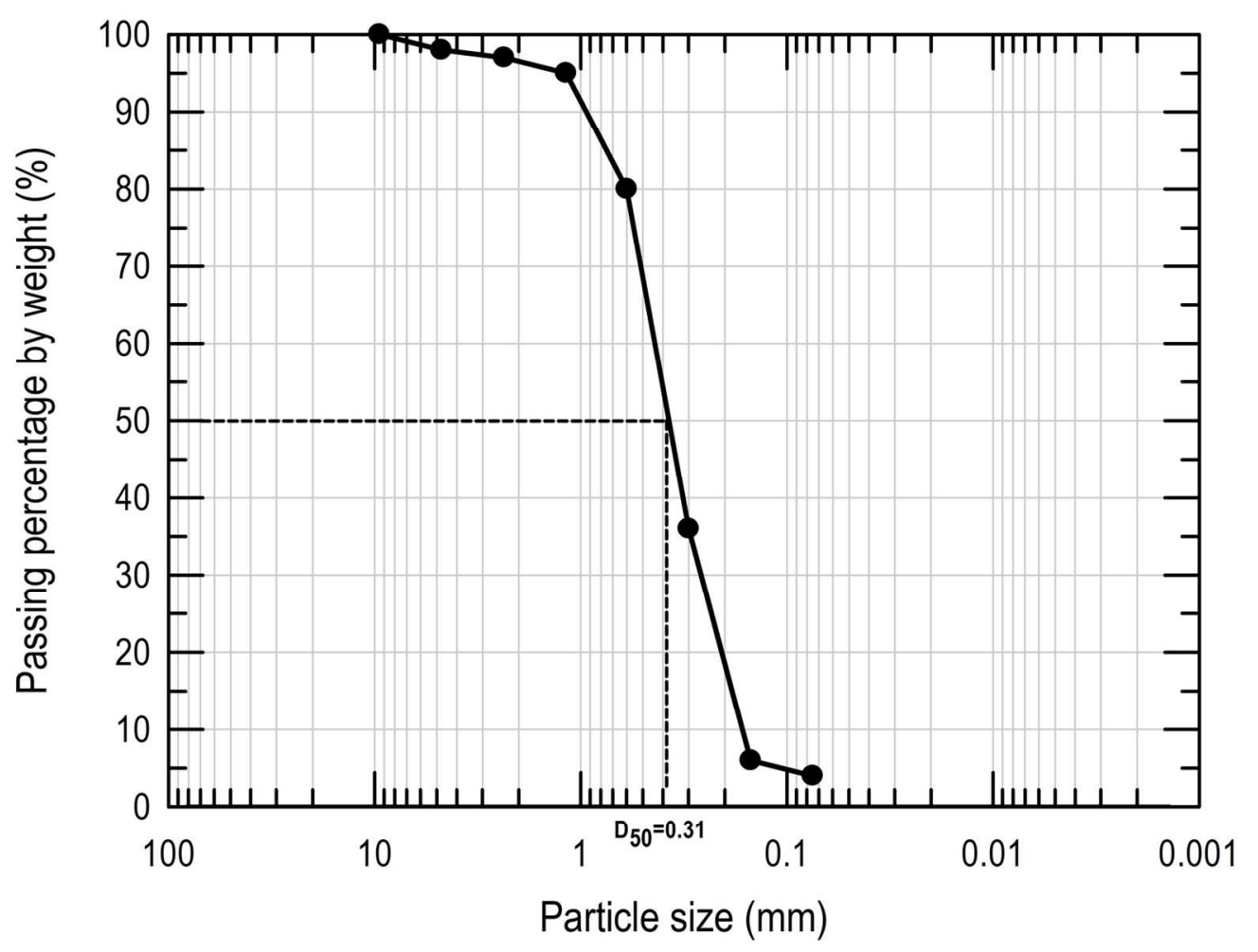

Fig. 3. Typical particle size distribution in jet grout zone of test site $137 \times 103 \mathrm{~mm}(300 \times 300$ DPI $)$ 


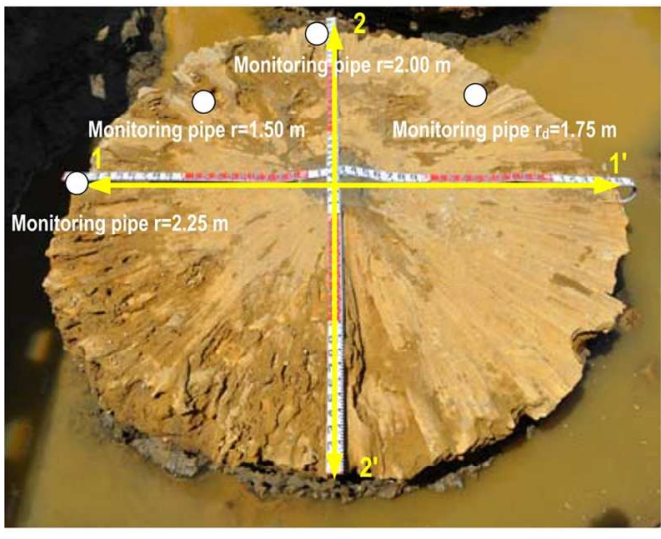

(a)
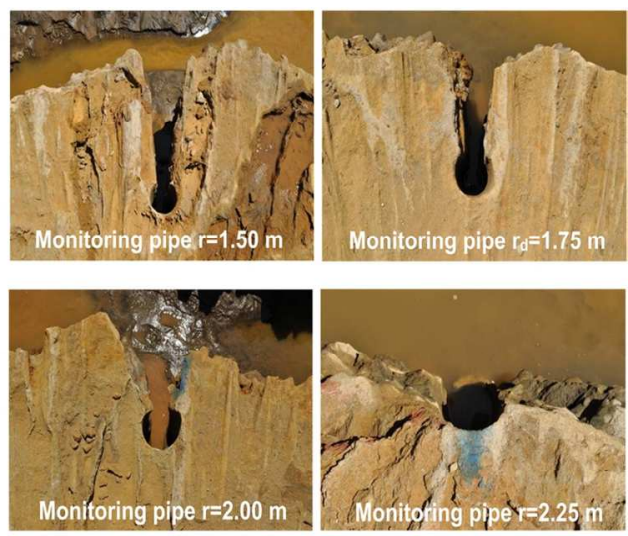

(b)

Fig. 4. Column dug out for actual measurements and visual inspection of jet cutting distance: (a) actual diameter measured; (b) monitoring pipe locations

$127 \times 56 \mathrm{~mm}(300 \times 300 \mathrm{DPI})$ 


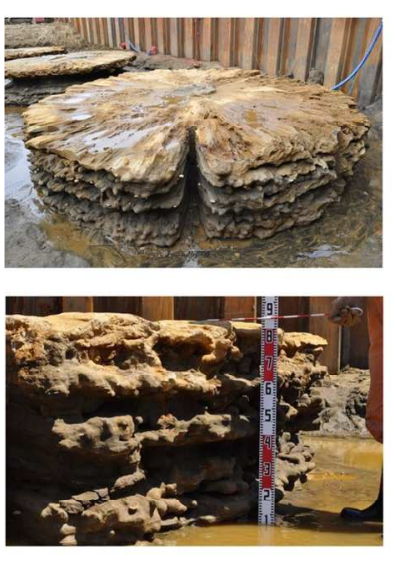

(a)

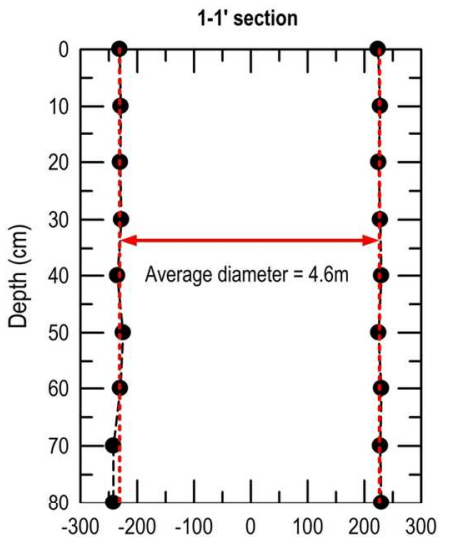

Measured diameter of jet grout column $(\mathrm{cm})$

(b)

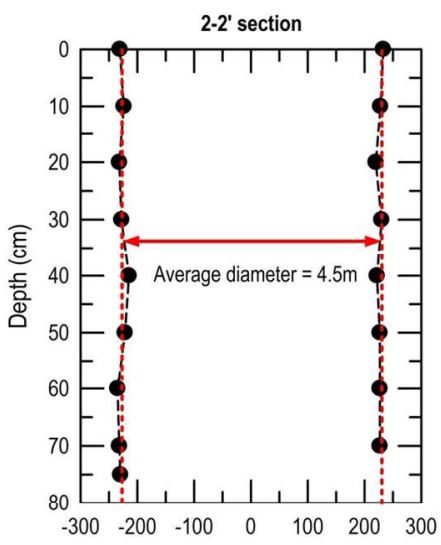

Measured diameter of jet grout column $(\mathrm{cm})$

(c)

Fig. 5. Actual jet grout column profile and measured diameter: (a) actual jet grout column; (b) measured diameter profile (1-1' section); (c) measured diameter profile (2-2' section)

$$
139 \times 66 \mathrm{~mm}(300 \times 300 \mathrm{DPI})
$$




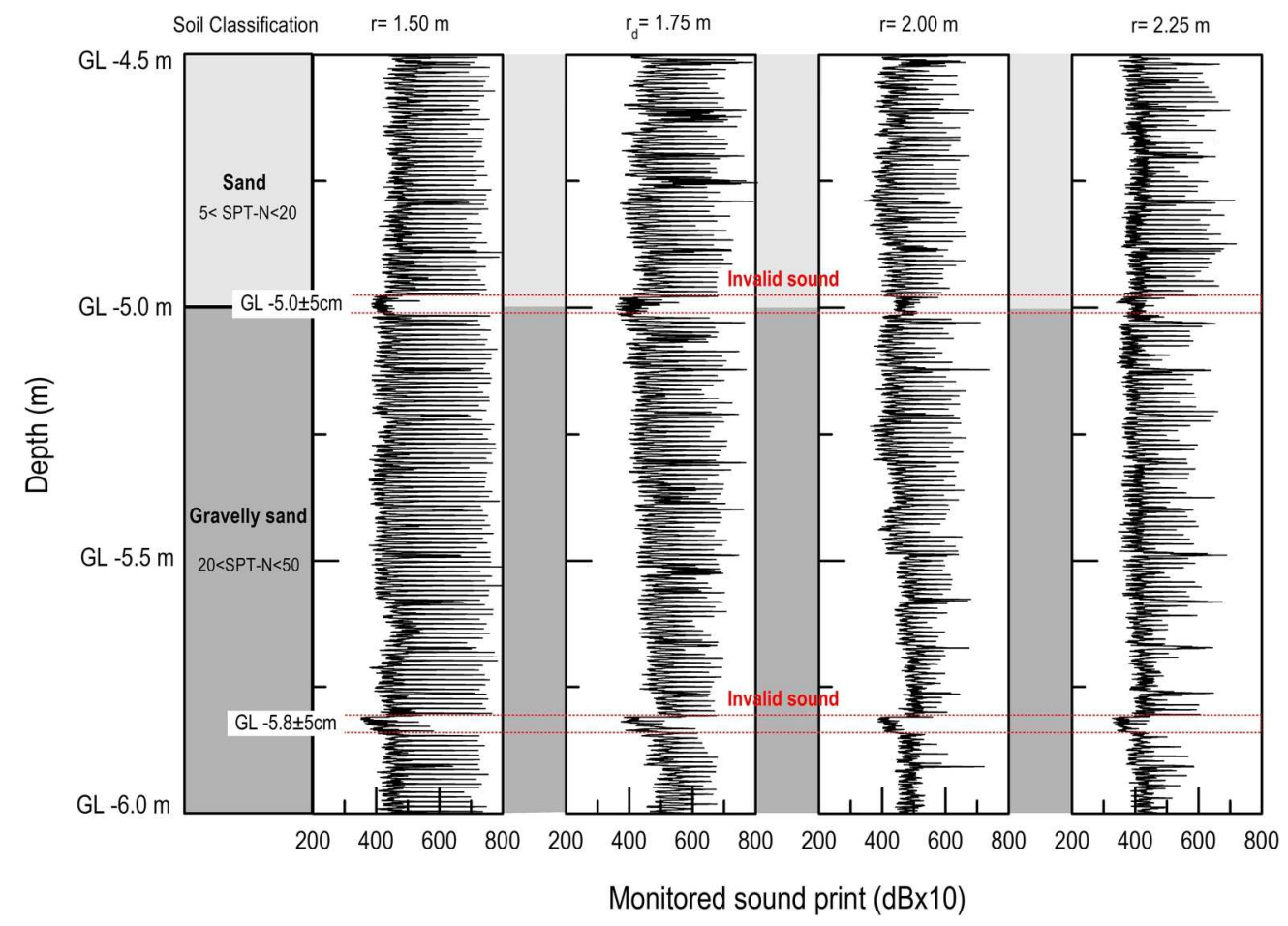

Fig. 6. Sound prints at multiple distances from the jet nozzle during jet grouting $181 \times 130 \mathrm{~mm}(300 \times 300 \mathrm{DPI})$ 


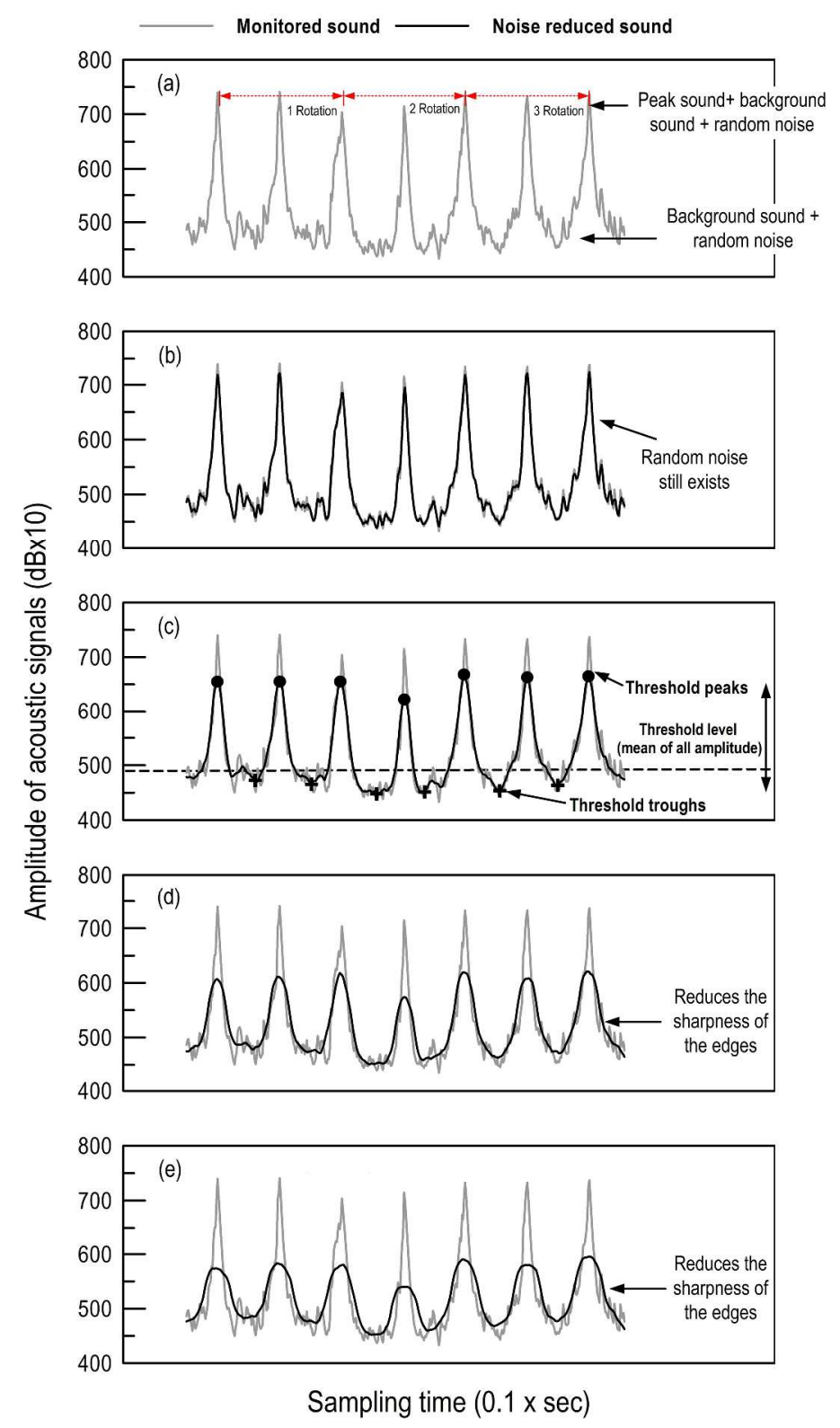

Fig. 7. Partial sound prints and time smoothing action of TSA processing: (a) monitored sound waveform;

(b) 3-point moving average; (c) 11-point moving average and POT processing; (d) 19-point moving average; (e) 27-point moving average

$294 \times 501 \mathrm{~mm}(300 \times 300$ DPI) 


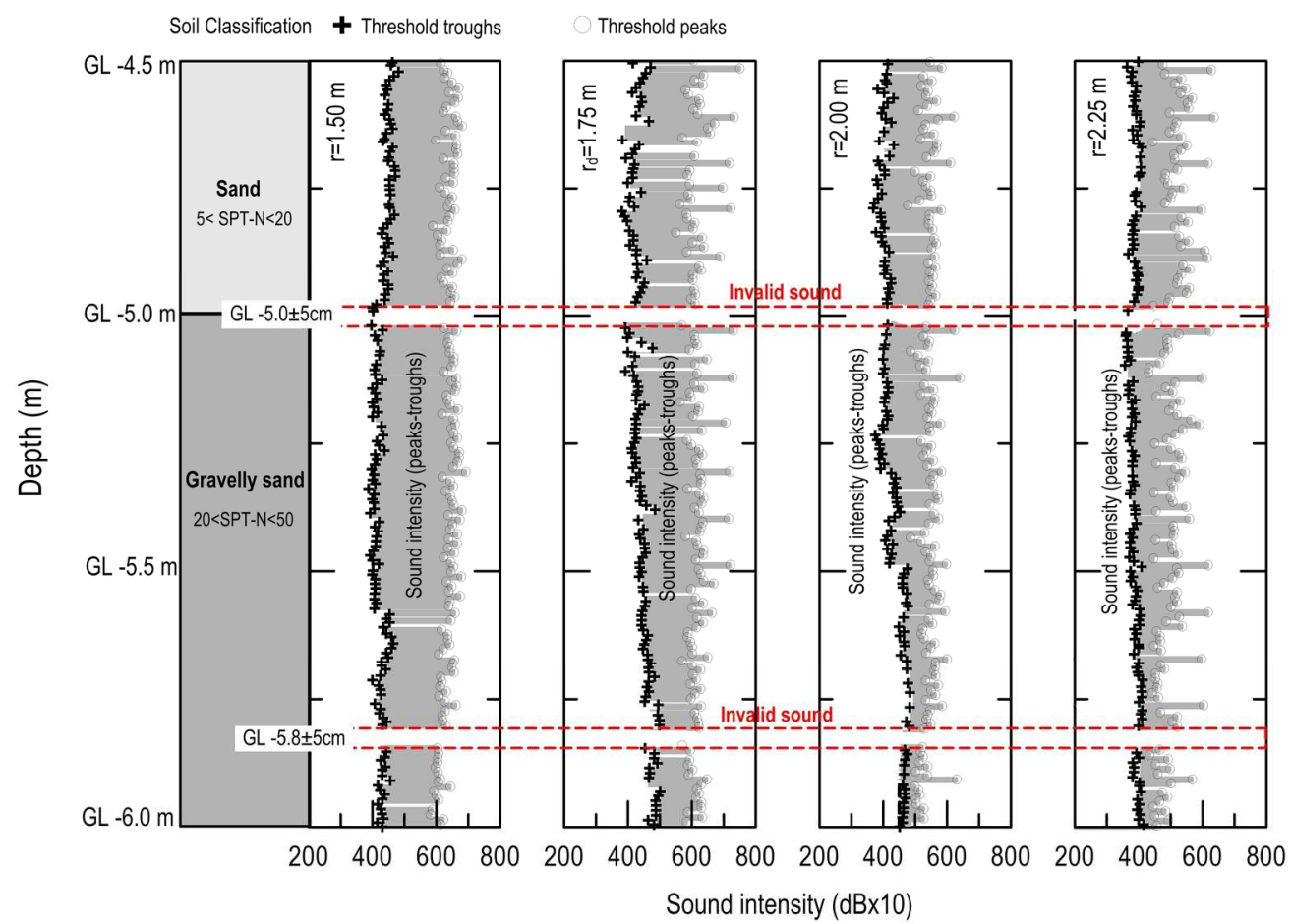

Fig. 8. Sound intensity and threshold peak/trough amplitudes at multiple distances from the jet nozzle $180 \times 128 \mathrm{~mm}(300 \times 300 \mathrm{DPI})$ 


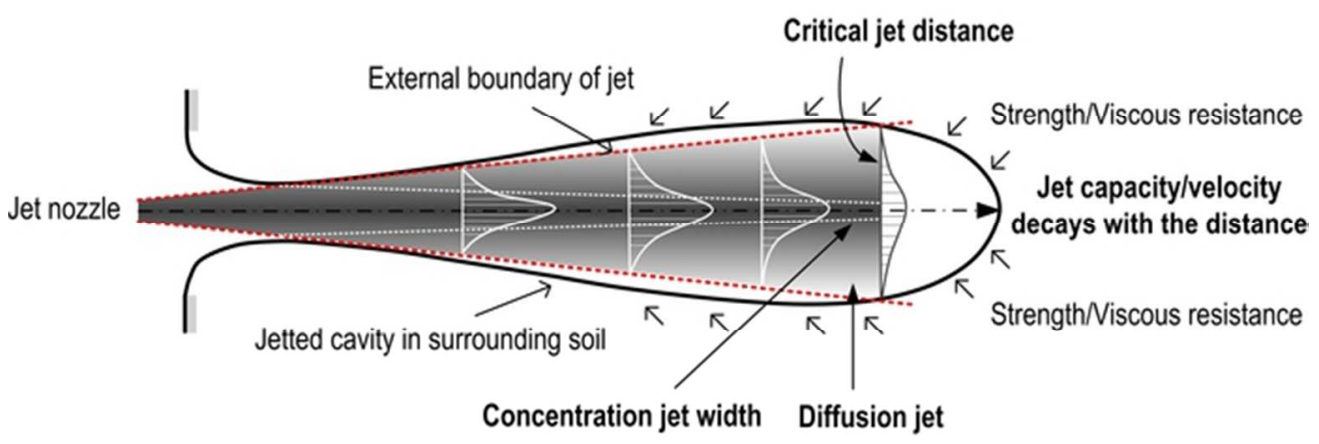

Fig. 9. Schematic of jet traveling through a viscous fluid and the attenuation characteristics $58 \times 19 \mathrm{~mm}(300 \times 300 \mathrm{DPI})$ 
Mean and standard deviations of threshold peak amplitudes(dBx10)

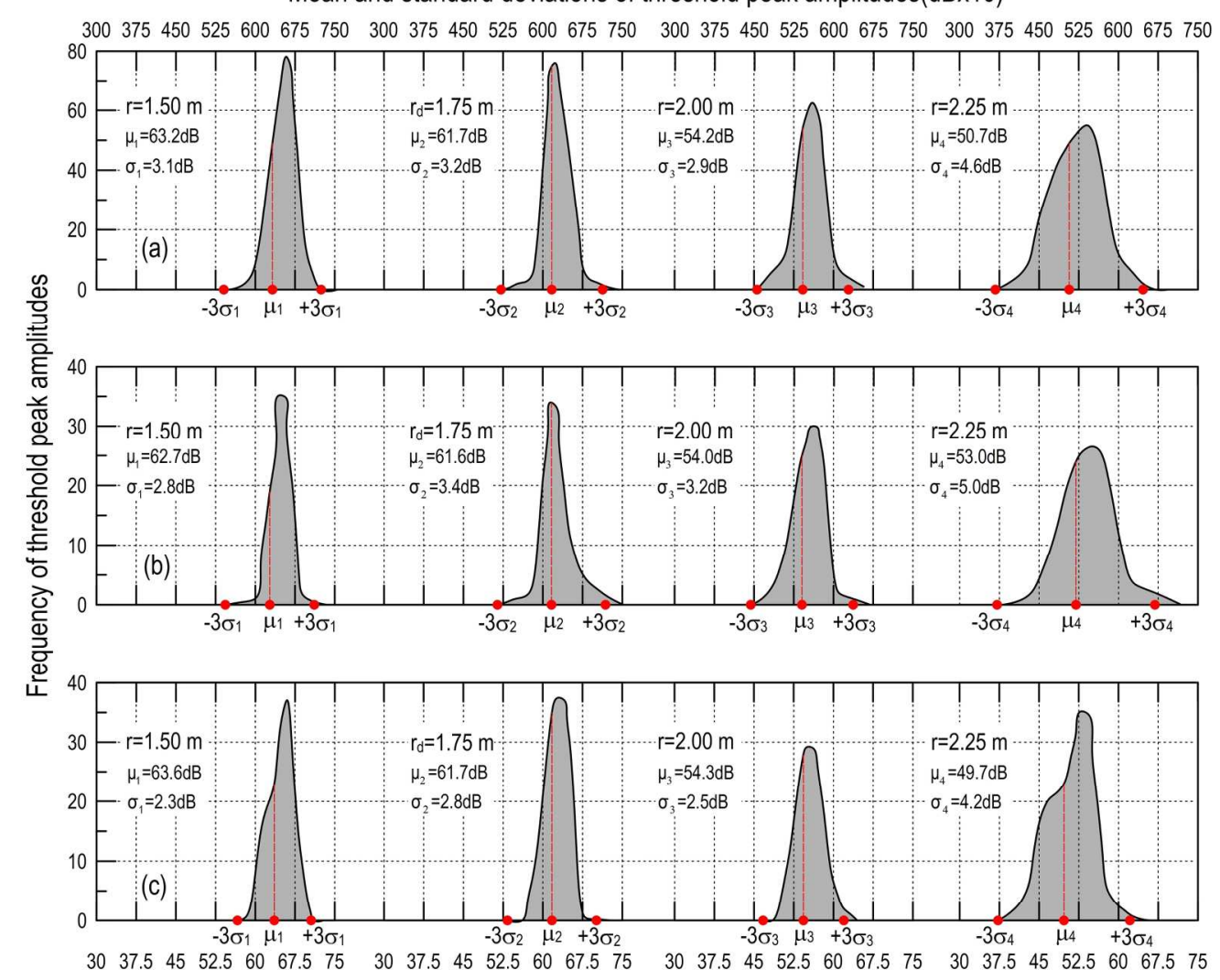

Mean and standard deviations of threshold peak amplitudes $(\mathrm{dB})$

Fig. 10. Normal distribution results of threshold peak amplitudes recorded at multiple distances from the jet nozzle: (a) sand/gravelly sand interlayer $(5<\mathrm{SPT}-\mathrm{N}<50)$; (b) sand layer $(5<\mathrm{SPT}-\mathrm{N}<20)$; (c) gravelly sand layer $(20<$ SPT $-\mathrm{N}<50)$

$187 \times 163 \mathrm{~mm}(300 \times 300 \mathrm{DPI})$ 

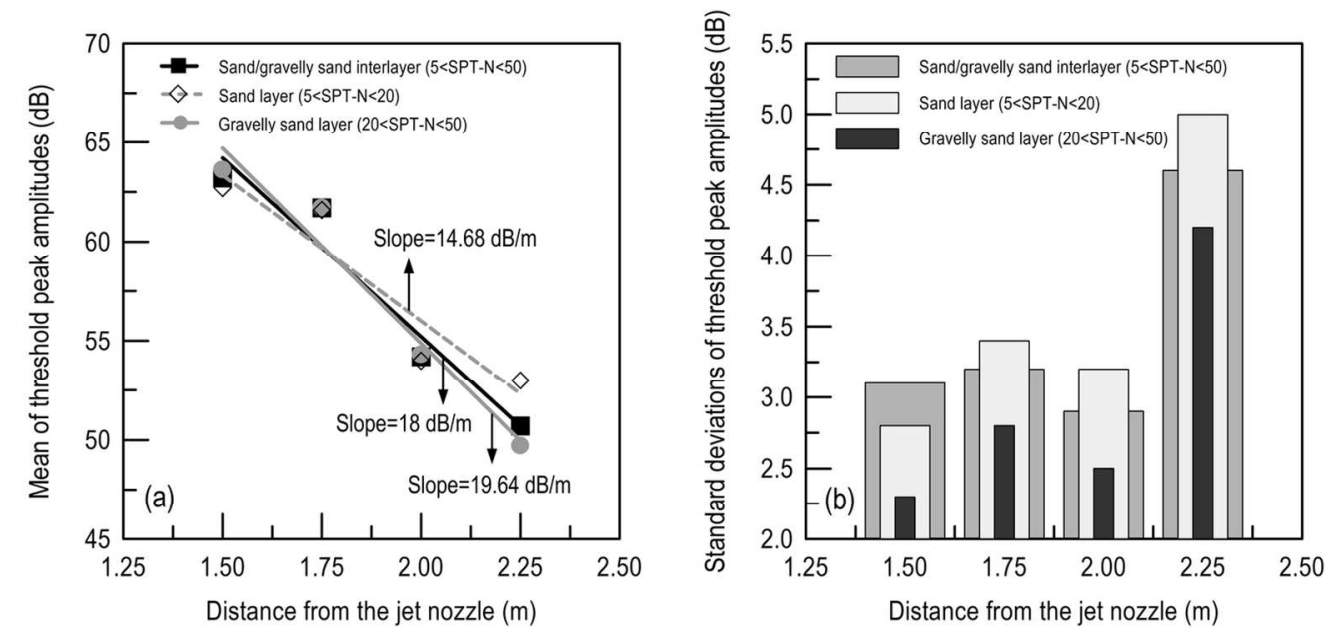

Fig. 11. Relationship between threshold peak amplitudes and distance from the jet nozzle (a) mean and attenuation rate; (b) standard deviation

$$
126 \times 60 \mathrm{~mm}(300 \times 300 \text { DPI) }
$$

